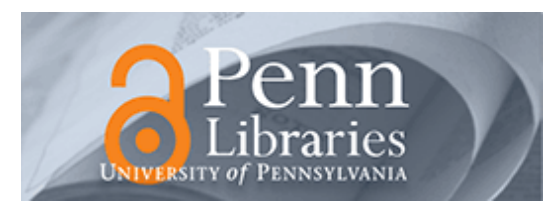

University of Pennsylvania ScholarlyCommons

Departmental Papers (Obstetrics and Gynecology)

Department of Obstetrics and Gynecology

$7-2018$

\title{
Mifepristone Pretreatment for the Medical Management of Early Pregnancy Loss
}

Courtney A. Schreiber

University of Pennsylvania, schreibe@upenn.edu

Mitchell D. Creinin

Jessica Atrio

Sarita Sonalkar

University of Pennsylvania, sarita.sonalkar@pennmedicine.upenn.edu

Sarah J. Ratcliffe

See next page for additional authors

Follow this and additional works at: https://repository.upenn.edu/obgyn_papers

Part of the Medicine and Health Sciences Commons

\section{Recommended Citation}

Schreiber, Courtney A.; Creinin, Mitchell D.; Atrio, Jessica; Sonalkar, Sarita; Ratcliffe, Sarah J.; and Barnhart, Kurt T., "Mifepristone Pretreatment for the Medical Management of Early Pregnancy Loss" (2018). Departmental Papers (Obstetrics and Gynecology). 3.

https://repository.upenn.edu/obgyn_papers/3

This paper is posted at ScholarlyCommons. https://repository.upenn.edu/obgyn_papers/3

For more information, please contact repository@pobox.upenn.edu. 


\section{Mifepristone Pretreatment for the Medical Management of Early Pregnancy Loss}

\section{Abstract \\ BACKGROUND}

Medical management of early pregnancy loss is an alternative to uterine aspira-tion, but standard medical treatment with misoprostol commonly results in treat-ment failure. We compared the efficacy and safety of pretreatment with mifepris-tone followed by treatment with misoprostol with the efficacy and safety of misoprostol use alone for the management of early pregnancy loss.

\section{METHODS}

We randomly assigned 300 women who had an anembryonic gestation or in whom embryonic or fetal death was confirmed to receive pretreatment with $200 \mathrm{mg}$ of mifepristone, administered orally, followed by $800 \mu \mathrm{g}$ of misoprostol, adminis-tered vaginally (mifepristone-pretreatment group), or $800 \mu \mathrm{g}$ of misoprostol alone, administered vaginally (misoprostol-alone group). Participants returned 1 to 4 days after misoprostol use for evaluation, including ultrasound examination, by an in-vestigator who was unaware of the treatment-group assignments. Women in whom the gestational sac was not expelled were offered expectant management, a second dose of misoprostol, or uterine aspiration. We followed all participants for 30 days after randomization. Our primary outcome was gestational sac expulsion with one dose of misoprostol by the first follow-up visit and no additional intervention within 30 days after treatment.

\section{RESULTS}

Complete expulsion after one dose of misoprostol occurred in 124 of 148 women (83.8\%; 95\% confidence interval [CI], 76.8 to 89.3) in the mifepristone-pretreat-ment group and in 100 of 149 women (67.1\%; $95 \%$ CI, 59.0 to 74.6 ) in the miso-prostol-alone group (relative risk, 1.25; 95\% CI, 1.09 to 1.43 ). Uterine aspiration was performed less frequently in the mifepristone-pretreatment group than in the misoprostol-alone group ( $8.8 \%$ vs. $23.5 \%$; relative risk, 0.37 ; $95 \%$ CI, 0.21 to 0.68 ). Bleeding that resulted in blood transfusion occurred in $2.0 \%$ of the women in the mifepristone-pretreatment group and in $0.7 \%$ of the women in the misoprostol-alone group $(\mathrm{P}=0.31)$; pelvic infection was diagnosed in $1.3 \%$ of the women in each group.

\section{CONCLUSIONS}

Pretreatment with mifepristone followed by treatment with misoprostol resulted in a higher likelihood of successful management of first-trimester pregnancy loss than treatment with misoprostol alone. (Funded by the National Institute of Child Health and Human Development; PreFaiR ClinicalTrials.gov number, NCT02012491.)

\section{Disciplines}

Medicine and Health Sciences

\section{Author(s)}

Courtney A. Schreiber, Mitchell D. Creinin, Jessica Atrio, Sarita Sonalkar, Sarah J. Ratcliffe, and Kurt T. Barnhart 


\title{
The NEW ENGLAND \\ JOURNAL of MEDICINE
}

ESTABLISHED IN 1812

JUNE 7, 2018

VOL. 378 NO. 23

\section{Mifepristone Pretreatment for the Medical Management of Early Pregnancy Loss}

\author{
Courtney A. Schreiber, M.D., M.P.H., Mitchell D. Creinin, M.D., Jessica Atrio, M.D., Sarita Sonalkar, M.D., M.P.H.,
} Sarah J. Ratcliffe, Ph.D., and Kurt T. Barnhart, M.D., M.S.C.E.

\section{ABSTRACT}

BACKGROUND

Medical management of early pregnancy loss is an alternative to uterine aspiration, but standard medical treatment with misoprostol commonly results in treatment failure. We compared the efficacy and safety of pretreatment with mifepristone followed by treatment with misoprostol with the efficacy and safety of misoprostol use alone for the management of early pregnancy loss.

\section{METHODS}

We randomly assigned 300 women who had an anembryonic gestation or in whom embryonic or fetal death was confirmed to receive pretreatment with $200 \mathrm{mg}$ of mifepristone, administered orally, followed by $800 \mu \mathrm{g}$ of misoprostol, administered vaginally (mifepristone-pretreatment group), or $800 \mu \mathrm{g}$ of misoprostol alone, administered vaginally (misoprostol-alone group). Participants returned 1 to 4 days after misoprostol use for evaluation, including ultrasound examination, by an investigator who was unaware of the treatment-group assignments. Women in whom the gestational sac was not expelled were offered expectant management, a second dose of misoprostol, or uterine aspiration. We followed all participants for 30 days after randomization. Our primary outcome was gestational sac expulsion with one dose of misoprostol by the first follow-up visit and no additional intervention within 30 days after treatment.

\section{RESULTS}

Complete expulsion after one dose of misoprostol occurred in 124 of 148 women (83.8\%; 95\% confidence interval [CI], 76.8 to 89.3 ) in the mifepristone-pretreatment group and in 100 of 149 women $(67.1 \%$; 95\% CI, 59.0 to 74.6$)$ in the misoprostol-alone group (relative risk, 1.25; 95\% CI, 1.09 to 1.43). Uterine aspiration was performed less frequently in the mifepristone-pretreatment group than in the misoprostol-alone group ( $8.8 \%$ vs. $23.5 \%$; relative risk, 0.37 ; $95 \%$ CI, 0.21 to 0.68 ). Bleeding that resulted in blood transfusion occurred in $2.0 \%$ of the women in the mifepristone-pretreatment group and in $0.7 \%$ of the women in the misoprostolalone group $(\mathrm{P}=0.31)$; pelvic infection was diagnosed in $1.3 \%$ of the women in each group.

\section{CONCLUSIONS}

Pretreatment with mifepristone followed by treatment with misoprostol resulted in a higher likelihood of successful management of first-trimester pregnancy loss than treatment with misoprostol alone. (Funded by the National Institute of Child Health and Human Development; PreFaiR ClinicalTrials.gov number, NCT02012491.)
From the Pregnancy Early Access Center (PEACE), Division of Family Planning (C.A.S., S.S.), Department of Obstetrics and Gynecology (C.A.S., S.S., K.T.B.), University of Pennsylvania, Philadelphia; the Department of Public Health Sciences, University of Virginia, Charlottesville (S.J.R.); the Department of Obstetrics and Gynecology, University of California, Davis, Sacramento (M.D.C.); and the Department of Obstetrics and Gynecology, Montefiore Hospital and Albert Einstein College of Medicine, Bronx, NY (J.A.). Address reprint requests to $\mathrm{Dr}$. Schreiber at the Department of Obstetrics and Gynecology, University of Pennsylvania, Philadelphia, PA 19104, or at schreibe@ upenn.edu.

N EngIJ Med 2018;378:2161-70. DOI: 10.1056/NEJMoal715726

Copyright () 2018 Massachusetts Medical Society. 
$\mathrm{F}$ IRST-TRIMESTER MISCARRIAGE, OR EARLY pregnancy loss, is the most common complication in pregnancy and affects approxi-

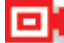

A Quick Take is available at NEJM.org mately 1 million women in the United States annually. ${ }^{1,2}$ Subtypes of early pregnancy loss include anembryonic gestation and embryonic or fetal death, inevitable abortion, and incomplete abortion. ${ }^{3,4}$ Before the advent of home pregnancy testing and early ultrasonography, women often presented with heavy bleeding or signs of infection requiring prompt treatment with dilation and curettage. ${ }^{5}$ Currently, women frequently receive a diagnosis of early pregnancy loss before the onset of symptoms. This decrease in exigent presentations has led to an interest in pursuing nonsurgical treatment options for pregnancy loss. ${ }^{6,7}$ Although some women pursue expectant management, women generally prefer active management ${ }^{6,8-12}$; the ability to have control over the management of miscarriage may relieve some of the emotional burden that accompanies firsttrimester pregnancy loss. ${ }^{12-14}$

Medical management of early pregnancy loss with prostaglandin analogues allows for planned, expedited expulsion of the nonviable pregnancy tissue, with the goal of avoiding a surgical procedure. Misoprostol is stable at room temperature and can be administered by the woman herself, which allows the tissue expulsion to occur in the privacy of a woman's home at a time she chooses. ${ }^{15}$ Medical management is highly desired by many women, and the use of misoprostol is recommended by society guidelines in the United States and throughout the world. ${ }^{16,17}$ Unfortunately, the standard dose of $800 \mu \mathrm{g}$ of misoprostol, administered vaginally, has low efficacy among women with a closed cervical os. As many as 15 to $40 \%$ of such women require a second dose of misoprostol, which prolongs the treatment period, or ultimately require the uterine evacuation procedure they wished to avoid., 3,-9,18 The rate of failure diminishes the clinical usefulness of this strategy in practice. ${ }^{12}$

Mifepristone is a 19-nor steroid that acts as a competitive progesterone-receptor antagonist and a glucocorticoid-receptor antagonist and primes the myometrium and cervix for prostaglandin activity. ${ }^{15,19,20}$ The reported effectiveness of combination treatment with mifepristone and misoprostol for early pregnancy loss has ranged from 52 to $95 \% .3,10,11,21,22$ This wide range is due in part to heterogeneity in study designs and outcome definitions. ${ }^{3}$ To date, the usefulness of mifepristone in the treatment of early pregnancy loss has remained unclear. We performed a randomized trial to compare the efficacy and safety of pretreatment with mifepristone followed by treatment with misoprostol with misoprostol use alone for the management of anembryonic gestation and embryonic or fetal death in women in clinically stable condition who have a closed cervical os.

METHODS

\section{TRIAL DESIGN}

From May 2014 through April 2017, women who received a diagnosis of anembryonic gestation or embryonic or fetal death were referred to the study team for screening; an investigator confirmed eligibility before enrollment. All participants provided written informed consent. The Comparative Effectiveness of Pregnancy Failure Management Regimens (PreFaiR) trial was approved by the institutional review boards at the University of Pennsylvania, the University of California, Davis, and the Albert Einstein College of Medicine. All the authors vouch for the completeness and accuracy of the data and analyses and for the fidelity of the trial to the protocol. Mifepristone (Mifeprex) was purchased from the manufacturer (Danco Laboratories) at a research price for use in the trial and was dispensed at the trial sites; the manufacturer had no other role in the trial. The protocol, including the statistical analysis plan, is available with the full text of this article at NEJM.org.

\section{PARTICIPANTS}

Healthy women 18 years of age or older were eligible if they had an ultrasound examination that showed a nonviable intrauterine pregnancy between 5 and 12 completed weeks of gestation. We excluded women who had an incomplete or inevitable abortion (defined as the absence of a gestational sac, an open cervical os, or both) because of the high efficacy of misoprostol use alone in women with these diagnoses. ${ }^{4}$ Women were also excluded if they had a contraindication to mifepristone or misoprostol, had any evidence of a viable or ectopic pregnancy, had a hemoglobin level lower than $9.5 \mathrm{~g}$ per deciliter, had a 
known clotting defect or were receiving anticoagulants, had a pregnancy with an intrauterine device in place, or were unwilling to adhere to the trial protocol.

\section{TRIAL PROCEDURES}

We randomly assigned the participants to receive pretreatment with $200 \mathrm{mg}$ of mifepristone, administered orally, followed by $800 \mu \mathrm{g}$ of misoprostol, administered vaginally approximately 24 hours later (mifepristone-pretreatment group), or standard therapy with $800 \mu \mathrm{g}$ of misoprostol alone, administered vaginally (misoprostol-alone group), on trial day 1. Participants were randomly assigned in permuted blocks of two to eight, stratified according to trial site, with the use of Research Electronic Data Capture software (REDCap, Vanderbilt University). Women who were assigned to the mifepristone-pretreatment group swallowed the mifepristone in front of one of the trial staff members. In accordance with our pragmatic trial design, the women in the misoprostol-alone group did not receive placebo. ${ }^{23}$ We instructed all participants in both treatment groups to insert four misoprostol tablets (200 $\mu \mathrm{g}$ per tablet) vaginally at home approximately 24 hours after randomization. We offered women oral analgesics according to the local standards at each trial site. Trial staff provided each participant a diary to record information about bleeding, symptoms, and pain medication use. Participants were scheduled for an initial follow-up appointment at least 24 hours (but not more than 4 days) after misoprostol use (trial day 3).

At the initial follow-up visit, an investigator who was unaware of the treatment-group assignments assessed the outcome by means of endovaginal ultrasonography. If the gestational sac was absent, a follow-up telephone call was scheduled approximately 1 week after randomization. If the gestational sac was present, we offered women a second dose of misoprostol or expectant or surgical management. Participants who chose expectant management or a second dose of misoprostol returned for an additional follow-up visit approximately 8 days (range, 6 to 12) after randomization for evaluation by an investigator who was unaware of the treatmentgroup assignments. We contacted all participants by telephone 30 days (range, 25 to 36) after randomization to collect information about additional treatments or adverse events. At this time, participants assessed bleeding and pain (on Likert scales, on which scores ranged from 1 to 5 , with lower scores indicating greater bleeding and pain) and responded to standard questions regarding the acceptability of treatment. ${ }^{8,24,25}$

\section{OUTCOMES AND ADVERSE EVENTS}

The primary outcome was gestational sac expulsion by the first follow-up visit with one dose of misoprostol and no additional surgical or medical intervention within 30 days after treatment; the attainment of the primary outcome was classified as treatment success. We chose this primary outcome in accordance with patient preferences for the treatment to work promptly and effectively. We also planned assessments of the treatment outcomes at the day 8 and day 30 time points according to three commonly used clinical metrics: the rate of gestational sac expulsion with one dose of misoprostol, the rate of gestational sac expulsion with two doses of misoprostol, and the percentage of women who underwent uterine aspiration. Additional prespecified secondary outcomes (for which results are presented in the current report) included adverse effects (including bleeding and pain, as measured on Likert scales), acceptability of treatment (an overall assessment of the treatment, as measured on a 3-point scale [with "good" indicating a positive experience, "bad" a negative experience, or neutral] and with the question, "Would you recommend this method of treatment to a friend?"), and assessment of clinical characteristics associated with complete gestational sac expulsion; assessments of quality of life, costs, and biomarkers that predict complete gestational sac expulsion were performed, but the data are not presented here.

\section{STATISTICAL ANALYSIS}

On the basis of previous research, we expected the rate of treatment success with a single dose of misoprostol to be 80 to $90 \%$ in the mifepristone-pretreatment group and 60 to $71 \%$ in the misoprostol-alone group. ${ }^{8,10,18}$ We estimated that a sample size of 134 participants per treatment group would provide adequate power to detect a 15 percentage-point difference in the rate of treatment success $(85 \%$ in the mifepristone- 


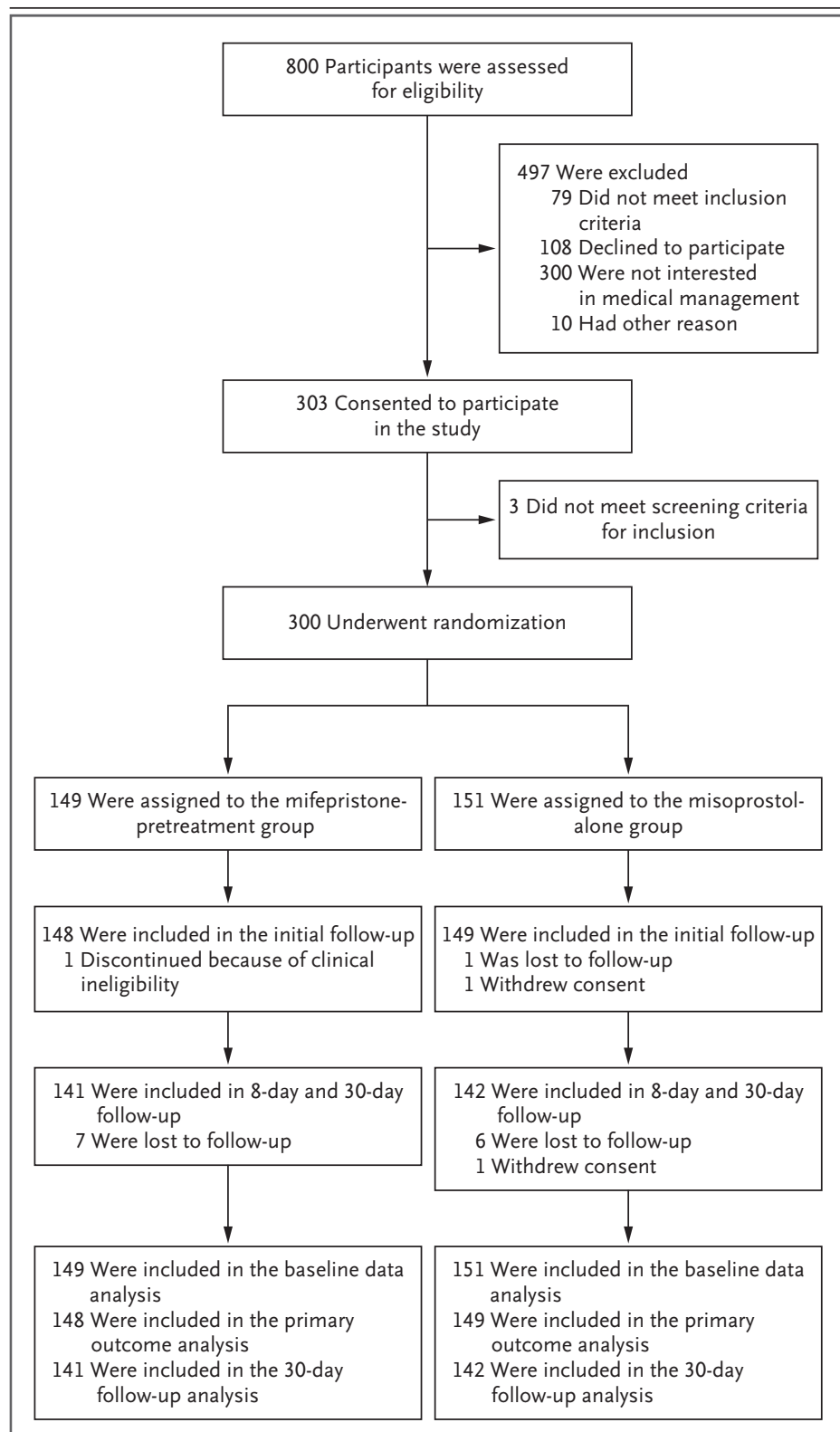

Figure 1. Enrollment, Randomization, Follow-up, and Analysis.

Participants assigned to the mifepristone-pretreatment group received $200 \mathrm{mg}$ of mifepristone, administered orally, followed by $800 \mu \mathrm{g}$ of misoprostol, administered vaginally approximately 24 hours later, and those assigned to the misoprostol-alone group received $800 \mu \mathrm{g}$ of misoprostol alone, administered vaginally. All participants received the assigned treatment.

pretreatment group vs. $70 \%$ in the misoprostolalone group). Allowing for a single interim analysis under a group sequential design and a loss to follow-up of $5 \%$, we set an overall re- cruitment goal of 300 women. Data analysis were performed with Stata software, version 15 (StataCorp). Standard descriptive methods were used to summarize the trial population overall and by treatment group. The primary outcome was assessed among all women who had at least one follow-up visit according to a preplanned modified intention-to-treat principle. After testing for homogeneity of the primary outcome among trial sites, we calculated the percentage (with 95\% confidence interval) of women in each treatment group who had treatment success and compared the results using two-sided MantelHaenszel combined relative risks at an alpha level of 0.047 (an alpha level of 0.003 was allocated to the interim analysis). We computed the effect of loss to follow-up by performing a sensitivity analysis in which the outcome that was most in favor of no treatment effect (i.e., failure in the mifepristone-pretreatment group and success in the misoprostol-alone group) was assigned to each participant who was lost to follow-up.

Subgroup analyses of the primary outcome according to patient demographics and clinical characteristics were prespecified; we performed analyses that were stratified according to gestational age, parity, gravidity, and diagnosis (embryonic or fetal death vs. anembryonic gestation). (The protocol also specified an analysis according to presenting symptoms, but this was not performed owing to the low percentage of participants who presented with bleeding.) Twosided Mantel-Haenszel combined relative risks were used to compare treatment groups in all secondary analyses; the results are presented without adjustment for multiplicity and should be considered exploratory. In accordance with the protocol, the data and safety monitoring committee performed one interim analysis for safety and futility after recruitment of half the participants; on the basis of the findings from this interim analysis, the trial was continued.

\section{RESULTS}

\section{PARTICIPANTS}

From May 2014 through April 2017, we assessed 800 women for eligibility; 497 women were excluded and 303 consented to participate (Fig. 1). The most common reason for declining participation was a preference for uterine aspiration 
over medical management. Of the 303 women enrolled, 3 did not meet screening criteria for inclusion; thus, 300 women underwent randomization, with 149 assigned to the mifepristonepretreatment group and 151 assigned to the misoprostol-alone group. All the participants completed the trial according to the protocol with the exception of 2 women who were lost to follow-up and 1 woman who was determined to be clinically ineligible after randomization because of suspicion of a cesarean-section-scar ectopic pregnancy (an ectopic pregnancy implanted in scar tissue from a previous cesarean section). Baseline characteristics were similar in the two treatment groups (Table 1).

\section{OUTCOMES}

\section{Initial Follow-up}

The median number of days between the time of misoprostol administration and the first followup visit was 2.0 (range, 0.5 to 5.5 ) in the mifepristone-pretreatment group and 2.6 (range, 0.7 to 9.6) in the misoprostol-alone group $(\mathrm{P}=0.04)$. Treatment success by the first follow-up visit, with no additional interventions needed within 30 days after treatment, occurred in 124 of 148 women $(83.8 \%$; 95\% confidence interval [CI], 76.8 to 89.3) in the mifepristone-pretreatment group and in 100 of 149 women $(67.1 \%$; 95\% CI, 59.0 to 74.6 ) in the misoprostol-alone group (absolute difference in the rate of treatment success, 16.7 percentage points [ $95 \% \mathrm{CI}, 7.1$ to 26.3]; relative risk of expulsion with one dose of misoprostol, 1.25 [95\% CI, 1.09 to 1.43]) (Table 2). The results were similar in a sensitivity analysis that assumed that the outcomes in the women who were lost to follow-up were most in favor of no treatment effect (i.e., treatment failure with mifepristone pretreatment and treatment success with misoprostol alone) (relative risk, 1.21 ; $95 \% \mathrm{CI}, 1.05$ to 1.38 ). In the mifepristone-pretreatment group, 65 women $(43.6 \%)$ did not wait the full 24 hours before administering misoprostol (mean $[ \pm \mathrm{SD}]$ number of hours waited, 12.0 \pm 7.3$)$, of whom 45 (69.2\%) waited for less than 18 hours. The rate of treatment success among women who not wait the full 24 hours before administering misoprostol was $79.7 \%$, as compared with $86.9 \%$ among the women who waited for 24 hours $(P=0.24)$. The number needed to pretreat with mifepristone to attain an additional outcome of treatment success by the first follow-up visit was 6 .

\section{Day 8 Follow-up}

Gestational sac expulsion did not occur by the first follow-up visit in 24 women in the mifepristone-pretreatment group (16.2\%) and in 49 women in the misoprostol-alone group (32.9\%); among these women, $41 \%$ chose expectant management, $27 \%$ chose a second dose of misoprostol, and 31\% underwent uterine aspiration (Table S1 in the Supplementary Appendix, available at NEJM.org). Among the women who did not have treatment success by the first follow-up visit, there were no significant between-group differences in the proportion of women who chose each additional intervention $(\mathrm{P}=0.12)$. Complete expulsion of the gestational sac with one dose of misoprostol by day 8 occurred in 130 of 148 women $(87.8 \%$; $95 \%$ CI, 81.5 to 92.6 ) in mifepristone-pretreatment group and in 106 of 149 women $(71.1 \%$; 95\% CI, 63.2 to 78.3$)$ in the misoprostol-alone group (relative risk, 1.23; $95 \%$ CI, 1.10 to 1.39 ).

\section{Day 30 Follow-up}

One month after randomization, the cumulative rate of gestational sac expulsion with up to two doses of misoprostol was $91.2 \%$ (95\% CI, 85.4 to 95.2 ) in the mifepristone-pretreatment group and $75.8 \%$ (95\% CI, 68.2 to 82.5 ) in the misoprostol-alone group. By the end of the trial period at day 30 , a total of 13 women $(8.8 \%$; $95 \%$ CI, 4.8 to 14.6) in the mifepristone-pretreatment group and 35 women (23.5\%; 95\% CI, 16.9 to $31.1)$ in the misoprostol-alone group had undergone uterine aspiration (absolute difference, 14.7 percentage points [95\% CI, 6.5 to 22.9]; relative risk, 0.37 [95\% CI, 0.21 to 0.68]) (Table 2).

We performed subgroup analyses stratified according to length of gestation, parity, gravidity, and diagnosis (embryonic or fetal death vs. anembryonic gestation). Rates of treatment success by the first follow-up visit among women who were at 9 weeks of gestation or less were $84.8 \%$ (117 of 138 women) in the mifepristone-pretreatment group and $66.7 \%$ (94 of 141 women) in the misoprostol-alone group. No significant betweengroup differences were found in the effect of the intervention according to subgroups stratified by gestation, gravidity, parity, or diagnosis (Fig. 2). 


\begin{tabular}{|c|c|c|}
\hline Characteristic & $\begin{array}{l}\text { Mifepristone-Pretreatment } \\
\text { Group } \\
(\mathrm{N}=149)\end{array}$ & $\begin{array}{l}\text { Misoprostol-Alone } \\
\text { Group } \\
(\mathrm{N}=151)\end{array}$ \\
\hline Age $-y r$ & $30.7 \pm 6.3$ & $30.2 \pm 6.0$ \\
\hline \multicolumn{3}{|l|}{ Race or ethnic group — no. (\%) $\dagger$} \\
\hline Black & $65(43.6)$ & $67(44.4)$ \\
\hline White & $57(38.3)$ & $52(34.4)$ \\
\hline Hispanic & $38(25.5)$ & $38(25.5)$ \\
\hline Asian & $9(6.0)$ & $11(7.3)$ \\
\hline Other & $18(12.1)$ & $21(13.9)$ \\
\hline \multicolumn{3}{|l|}{ Educationł } \\
\hline Some grade school or high school & $10(6.8)$ & $17(11.3)$ \\
\hline High-school diploma or GED & $46(31.1)$ & $56(37.1)$ \\
\hline Some college or post-high-school education & $92(62.2)$ & $78(51.7)$ \\
\hline \multicolumn{3}{|l|}{ Medical insurance } \\
\hline None & $13(8.8)$ & $11(7.3)$ \\
\hline Medicaid or Medicare & $64(43.2)$ & $78(51.7)$ \\
\hline Private insurance & $71(48.0)$ & $62(41.1)$ \\
\hline \multicolumn{3}{|l|}{ Gravidity } \\
\hline 1 & $37(24.8)$ & $32(21.2)$ \\
\hline 2 & $36(24.2)$ & $27(17.9)$ \\
\hline$\geq 3$ & $76(51.0)$ & $92(60.9)$ \\
\hline \multicolumn{3}{|l|}{ Parity } \\
\hline 0 & $63(42.3)$ & $52(34.4)$ \\
\hline$\geq 1$ & $86(57.7)$ & 99 (65.6) \\
\hline Living children & $87(58.4)$ & $94(62.3)$ \\
\hline Previous miscarriage & $53(35.6)$ & $52(34.4)$ \\
\hline \multicolumn{3}{|l|}{ Gestation } \\
\hline $4-5 w k$ & $15(10.1)$ & $10(6.6)$ \\
\hline 6 wk & $44(29.5)$ & $38(25.2)$ \\
\hline 7 wk & $34(22.8)$ & $46(30.5)$ \\
\hline $8 w k$ & $31(20.8)$ & $34(22.5)$ \\
\hline $9 w k$ & $14(9.4)$ & $15(9.9)$ \\
\hline $10-12 \mathrm{wk}$ & $11(7.4)$ & $8(5.3)$ \\
\hline \multicolumn{3}{|l|}{ Diagnosis } \\
\hline Anembryonic gestation & $40(26.8)$ & $37(24.5)$ \\
\hline Embryonic or fetal death & $109(73.2)$ & $114(75.5)$ \\
\hline \multicolumn{3}{|l|}{ Any bleeding before randomization } \\
\hline Yes & $18(12.1)$ & $17(11.3)$ \\
\hline No & $111(74.5)$ & $119(78.8)$ \\
\hline Unknown & $20(13.4)$ & $15(9.9)$ \\
\hline \multicolumn{3}{|c|}{$\begin{array}{l}\text { * Plus-minus values are means } \pm \text { SD. Participants assigned to the mifepristone-pretreatment group received } 200 \mathrm{mg} \text { of } \\
\text { mifepristone, administered orally, followed by } 800 \mu \mathrm{g} \text { of misoprostol, administered vaginally approximately } 24 \text { hours } \\
\text { later, and those assigned to the misoprostol-alone group received } 800 \mu \mathrm{g} \text { of misoprostol alone, administered vaginally. } \\
\text { There were no significant differences between the groups in any of the characteristics listed. Percentages may not sum } \\
\text { to } 100 \text { because of rounding. } \\
\text { † Race and ethnic group were reported by the participants. } \\
\text { Tone participant in the mifepristone-pretreatment group was excluded because of missing values. }\end{array}$} \\
\hline
\end{tabular}




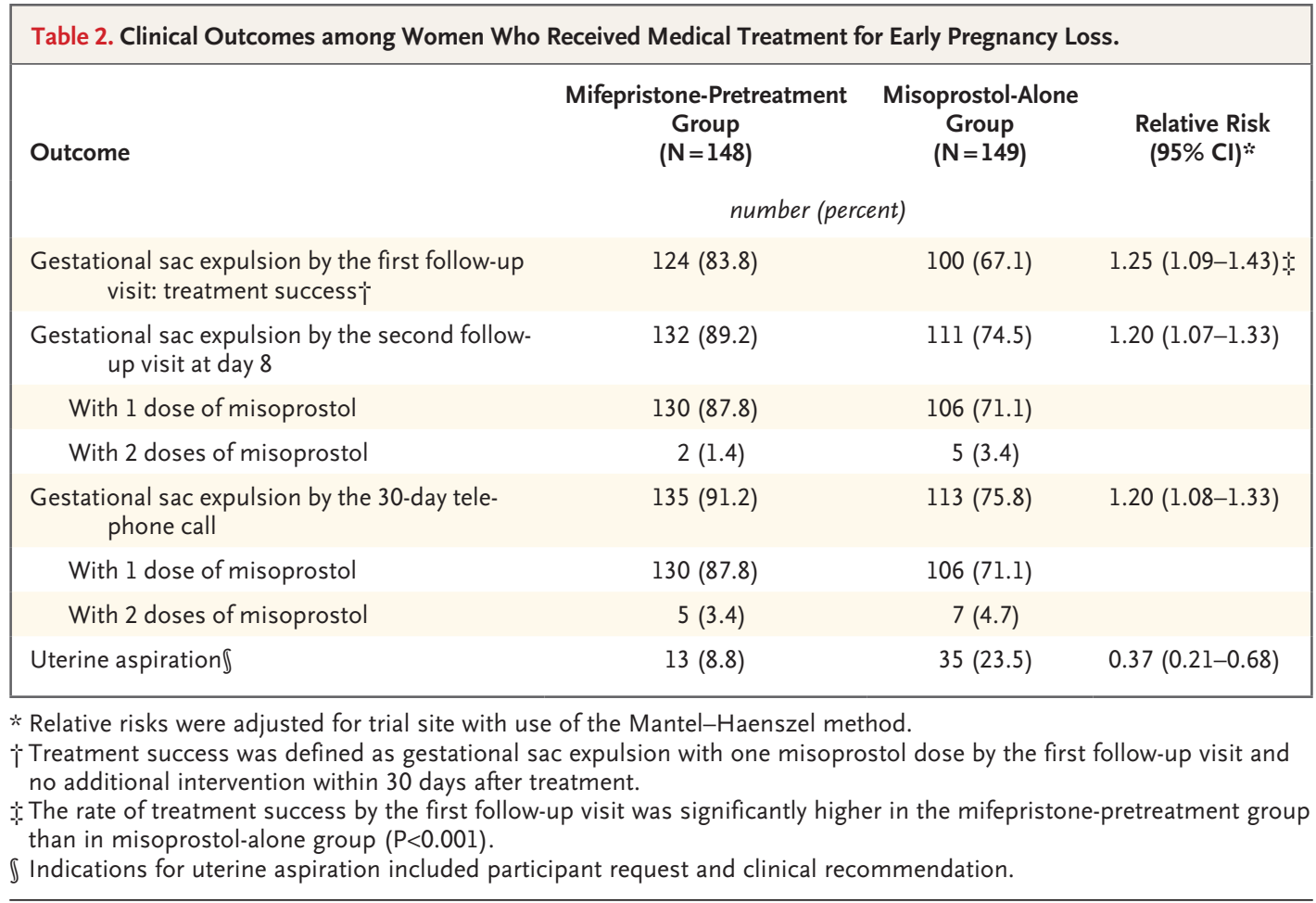

\section{SIDE EFFECTS AND ACCEPTABILITY OF TREATMENT}

The rates of serious adverse events and adverse events by type are provided in Table 3 . There were no significant between-group differences in the mean scores for bleeding intensity (1.8 in both groups) or pain (2.7 in both groups). By the end of the trial period, $89.4 \%$ of the women in the mifepristone-pretreatment group and $87.4 \%$ in the misoprostol-alone group described their experience overall as either "good" or "neutral"; the corresponding percentages of women who stated that they would recommend their treatment method to a friend were $87.0 \%$ and $89.6 \%$. The majority of women in each group $(69.1 \%$ in the mifepristone-pretreatment group and $64.8 \%$ the misoprostol-alone group) also stated that they would use medical management if they had another pregnancy loss.

\section{DISCUSSION}

In this randomized trial involving women with anembryonic gestation or in whom embryonic or fetal death was confirmed, pretreatment with mifepristone followed by treatment with misoprostol resulted in a significantly higher rate of complete gestational sac expulsion by approximately 2 days after treatment than misoprostol use alone. Pretreatment with mifepristone also resulted in a significantly lower rate of uterine aspiration than misoprostol use alone.

Even in the context of our pragmatic trial design in which women received routine clinical care after the first follow-up visit, we had high rates of participant retention and adherence to the protocol. Our trial population was diverse with respect to sociodemographic status and pregnancy diagnosis, which supports the generalizability of the results. We did not include a placebo group in this pragmatic trial. Because the primary outcome was not reported by the participants but was assessed by an investigator who was unaware of the treatment-group assignments, we do not expect that the lack of a placebo group introduced bias related to the primary outcome. It is possible that secondary efficacy outcomes could have been affected, because women in the misoprostol-alone group who did not have gestational sac expulsion by the first follow-up visit might have been less willing to wait (i.e., to choose expectant management) until day 8 for tissue expulsion than those in the mifepristone-pretreatment group, but we did not find that the proportion of additional interventions differed significantly between the treatment groups. We allowed for a short range of days at 


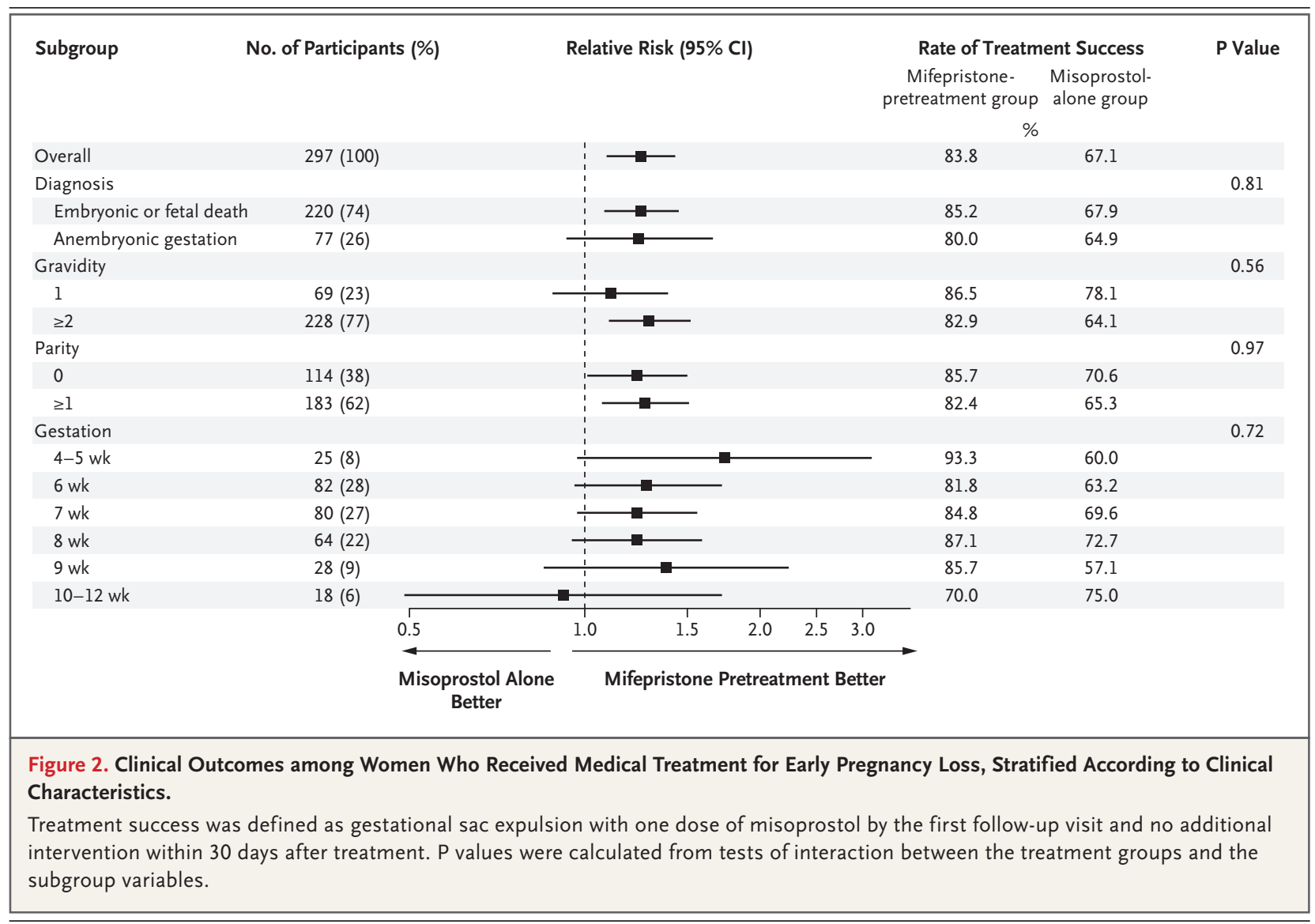

which we initially assessed the primary outcome to accommodate the scheduling preferences of the participants. The slightly longer mean elapsed time between misoprostol use and follow-up assessment in the misoprostol-alone group would have biased against the benefit of pretreatment, even though a significant benefit of pretreatment was found.

We evaluated the 800- $\mu \mathrm{g}$ dose of misoprostol, administered vaginally, because this dose and route of administration were best supported by the literature at the time of the development of our protocol. ${ }^{3,10,26}$ Misoprostol can also be administered orally, rectally, buccally, or sublingually. Administration through the buccal route results in uterine tone and activity that are similar to those with the vaginal route, ${ }^{27}$ and the sublingual route results in more rapid absorption and higher peak levels than the vaginal route. ${ }^{28}$ When misoprostol is used to induce a first-trimester abortion, vaginal administration is more effective than oral administration and may have fewer side effects than the sublingual or buccal route. ${ }^{29}$ Vaginal administration also permits efficacy at an interval of less than 24 hours after mifepristone administration among patients undergoing abortion..$^{25,30,31}$ Many of our participants chose not to wait the full 24 hours between mifepristone pretreatment and misoprostol use; future studies could test whether a shorter interval between the administration of these medications affects the efficacy of treatment for early pregnancy loss.

In 2000, the Food and Drug Administration first approved mifepristone for use with misoprostol to end an early pregnancy. This approval included Risk Evaluation and Mitigation Strategy requirements with the stated goal of mitigating the risk of serious complications associated with use of the drug. Although our study was not powered to show differences between groups in the proportions of serious adverse events, such events were rare - a finding that is consistent with the results of other published stud- 
Table 3. Adverse Events among Women Who Received Medical Treatment for Early Pregnancy Loss.

\begin{tabular}{|c|c|c|c|c|}
\hline Event & $\begin{array}{l}\text { Mifepristone-Pretreatment } \\
\text { Group } \\
(\mathrm{N}=149)\end{array}$ & $\begin{array}{l}\text { Misoprostol-Alone } \\
\text { Group } \\
(\mathrm{N}=151)\end{array}$ & $\begin{array}{c}\text { Relative Risk or } \\
\text { Incidence Rate Ratio } \\
(95 \% \mathrm{Cl})^{*}\end{array}$ & P Value \\
\hline \multicolumn{5}{|l|}{ Serious adverse events reported by participants } \\
\hline Total number (rate per 100 women $\dagger$ ) & $5(3.4)$ & $3(2.0)$ & $1.68(0.40-7.05)$ & 0.47 \\
\hline $\begin{array}{l}\text { Bleeding resulting in blood transfusion } \\
\quad \text { - no. of participants (\%) }\end{array}$ & $3(2.0)$ & $1(0.7)$ & $3.04(0.32-28.6)$ & 0.31 \\
\hline Pelvic infection - no. of participants $(\%) \Varangle$ & $2(1.3)$ & $2(1.3)$ & $1.01(0.15-7.01)$ & 0.99 \\
\hline \multicolumn{5}{|l|}{ Adverse events reported by participants } \\
\hline Total no. & 904 & 843 & & \\
\hline Mean no. per participant & 6.1 & 5.6 & $1.09(0.99-1.19)$ & 0.08 \\
\hline \multicolumn{5}{|l|}{ Type of event — no. of participants (\%) } \\
\hline Fatigue & $118(79.2)$ & $115(76.2)$ & $1.04(0.92-1.17)$ & 0.53 \\
\hline Headache & $88(59.1)$ & $72(47.7)$ & $1.24(1.00-1.54)$ & 0.05 \\
\hline Dizziness or lightheadedness & $78(52.3)$ & $68(45.0)$ & $1.16(0.92-1.47)$ & 0.20 \\
\hline Chills & $68(45.6)$ & $70(46.4)$ & $0.99(0.77-1.26)$ & 0.90 \\
\hline Nausea & $56(37.6)$ & $56(37.1)$ & $1.01(0.76-1.36)$ & 0.93 \\
\hline Diarrhea & $41(27.5)$ & $44(29.1)$ & $0.94(0.66-1.35)$ & 0.76 \\
\hline Vomiting & $40(26.8)$ & $23(15.2)$ & $1.76(1.11-2.79)$ & 0.01 \\
\hline Severe cramping & $20(13.4)$ & $21(13.9)$ & $0.97(0.58-1.61)$ & 0.90 \\
\hline Fever & $10(6.7)$ & $9(6.0)$ & $1.12(0.47-2.68)$ & 0.79 \\
\hline
\end{tabular}

* The rates for the total number of serious adverse events and mean number of adverse events were compared with the use of incidence rate ratios, with adjustment for trial site. The percentages of women who had each type of adverse event were compared with the use of relative risks that were adjusted for trial site with the Mantel-Haenszel method.

$\uparrow$ The rate per 100 women is shown to account for the fact that a woman could have more than one event.

7 Pelvic infection includes diagnoses of endometritis and septic abortion.

ies. ${ }^{11,21,24,26,32}$ Studies of the use of mifepristone for induced abortion or for the treatment of early pregnancy loss have not shown a risk profile that supports such regulatory limitations on prescription. ${ }^{33,34}$

In conclusion, this randomized trial showed that pretreatment with mifepristone followed by treatment with misoprostol resulted in a higher likelihood of prompt and effective treatment of early pregnancy loss than misoprostol use alone.
Supported by the National Institute of Child Health and Human Development of the National Institutes of Health (Eunice Kennedy Shriver award number R01-HD0719-20 [to Dr. Schreiber] and Women's Reproductive Health Research award number K12-HD001265-18 [to Dr. Sonalkar]).

Dr. Creinin reports receiving consulting fees from Danco Laboratories. No other potential conflict of interest relevant to this article was reported.

Disclosure forms provided by the authors are available with the full text of this article at NEJM.org.

We thank the members of the PreFaiR trial team and the data and safety monitoring committee, the study participants for their dedication, and Dr. Alan D. Schreiber, without whom this research would not have been possible.

\section{REFERENCES}

1. Casterline JB. Collecting data on pregnancy loss: a review of evidence from the World Fertility Survey. Stud Fam Plann 1989;20:81-95.

2. Ventura SJ, Curtin SC, Abma JC, Henshaw SK. Estimated pregnancy rates and rates of pregnancy outcomes for the Unit- ed States, 1990-2008. Natl Vital Stat Rep 2012;60:1-21.

3. Neilson JP, Hickey M, Vazquez J. Medical treatment for early fetal death (less than 24 weeks). Cochrane Database Syst Rev 2006;3:CD002253.

4. Kim C, Barnard S, Neilson JP, Hickey
M, Vazquez JC, Dou L. Medical treatments for incomplete miscarriage. Cochrane Database Syst Rev 2017;1:CD007223.

5. Hertig AT, Livingstone RG. Spontaneous, threatened and habitual abortion: their pathogenesis and treatment. $\mathrm{N}$ Engl J Med 1944;230:797-806. 
6. Jurkovic D. Modern management of miscarriage: is there a place for non-surgical treatment? Ultrasound Obstet Gynecol 1998;11:161-3.

7. Chen BA, Creinin MD. Contemporary management of early pregnancy failure. Clin Obstet Gynecol 2007;50:67-88.

8. Zhang J, Gilles JM, Barnhart K, Creinin MD, Westhoff C, Frederick MM. A comparison of medical management with misoprostol and surgical management for early pregnancy failure. $\mathrm{N}$ Engl J Med 2005;353:761-9.

9. Robledo C, Zhang J, Troendle J, et al. Clinical indicators for success of misoprostol treatment after early pregnancy failure. Int J Gynaecol Obstet 2007;99:4651.

10. Schreiber CA, Creinin MD, Reeves MF, Harwood BJ. Mifepristone and misoprostol for the treatment of early pregnancy failure: a pilot clinical trial. Contraception 2006;74:458-62.

11. Kollitz KM, Meyn LA, Lohr PA, Creinin MD. Mifepristone and misoprostol for early pregnancy failure: a cohort analysis. Am J Obstet Gynecol 2011; 204(5):386.e1-386.e6.

12. Schreiber CA, Chavez V, Whittaker PG, Ratcliffe SJ, Easley E, Barg FK. Treatment decisions at the time of miscarriage diagnosis. Obstet Gynecol 2016;128:134756.

13. Lee C, Slade P. Miscarriage as a traumatic event: a review of the literature and new implications for intervention. J Psychosom Res 1996;40:235-44.

14. Wallace RR, Goodman S, Freedman LR, Dalton VK, Harris LH. Counseling women with early pregnancy failure: utilizing evidence, preserving preference. Patient Educ Couns 2010;81:454-61.

15. Gemzell-Danielsson K, Bygdeman M, Aronsson A. Studies on uterine contractility following mifepristone and various routes of misoprostol. Contraception 2006; 74:31-5.
16. Committee on Practice Bulletins Gynecology. The American College of Obstetricians and Gynecologists practice bulletin no. 150: early pregnancy loss. Obstet Gynecol 2015;125:1258-67.

17. Weeks A. Medical treatment for early fetal death (less than 24 weeks): RHL commentary (last revised 4 January 2007). Geneva: WHO Reproductive Health Library, World Health Organization, 2007. 18. Creinin MD, Huang $X$, Westhoff $C$, Barnhart K, Gilles JM, Zhang J. Factors related to successful misoprostol treatment for early pregnancy failure. Obstet Gynecol 2006;107:901-7.

19. Baulieu EE. On the mechanism of action of RU486. Ann N Y Acad Sci 1991; 626:545-60.

20. Cheng L, Kelly RW, Thong KJ, Hume $\mathrm{R}$, Baird DT. The effect of mifepristone (RU486) on the immunohistochemical distribution of prostaglandin $\mathrm{E}$ and its metabolite in decidual and chorionic tissue in early pregnancy. J Clin Endocrinol Metab 1993;77:873-7.

21. Chia KV, Ogbo VI. Medical termination of missed abortion. J Obstet Gynaecol 2002;22:184-6.

22. Wagaarachchi PT, Ashok PW, Narvekar N, Smith NC, Templeton A. Medical management of early fetal demise using a combination of mifepristone and misoprostol. Hum Reprod 2001;16:1849-53.

23. Thorpe KE, Zwarenstein M, Oxman $\mathrm{AD}$, et al. A pragmatic-explanatory continuum indicator summary (PRECIS): a tool to help trial designers. J Clin Epidemiol 2009;62:464-75.

24. Creinin MD, Schwartz JL, Pymar HC, Fink W. Efficacy of mifepristone followed on the same day by misoprostol for early termination of pregnancy: report of a randomised trial. BJOG 2001;108:469-73.

25. Creinin MD, Schreiber CA, Bednarek P, Lintu H, Wagner MS, Meyn LA. Mifepristone and misoprostol administered simultaneously versus 24 hours apart for abortion: a randomized controlled trial. Obstet Gynecol 2007;109:885-94.

26. Ngoc NTN, Blum J, Westheimer E, Quan TTV, Winikoff B. Medical treatment of missed abortion using misoprostol. Int J Gynaecol Obstet 2004;87:138-42.

27. Meckstroth KR, Whitaker AK, Bertisch S, Goldberg AB, Darney PD. Misoprostol administered by epithelial routes: drug absorption and uterine response. Obstet Gynecol 2006;108:582-90.

28. Tang OS, Schweer H, Seyberth HW, Lee SW, Ho PC. Pharmacokinetics of different routes of administration of misoprostol. Hum Reprod 2002;17:332-6.

29. Kulier R, Kapp N, Gülmezoglu AM, Hofmeyr GJ, Cheng L, Campana A. Medical methods for first trimester abortion. Cochrane Database Syst Rev 2011;11: CD002855.

30. Creinin MD, Fox MC, Teal S, Chen A, Schaff EA, Meyn LA. A randomized comparison of misoprostol 6 to 8 hours versus 24 hours after mifepristone for abortion. Obstet Gynecol 2004;103:851-9.

31. Lohr PA, Reeves MF, Hayes JL, Harwood B, Creinin MD. Oral mifepristone and buccal misoprostol administered simultaneously for abortion: a pilot study. Contraception 2007;76:215-20.

32. Gronlund A, Grønlund L, Clevin L, Andersen B, Palmgren N, Lidegaard $\varnothing$. Management of missed abortion: comparison of medical treatment with either mifepristone + misoprostol or misoprostol alone with surgical evacuation: a multicenter trial in Copenhagen County, Denmark. Acta Obstet Gynecol Scand 2002; 81:1060-5.

33. Mifeprex REMS Study Group. Sixteen years of overregulation: time to unburden mifeprex. N Engl J Med 2017;376:790-4. 34. Cleland K, Smith N. Aligning mifepristone regulation with evidence: driving policy change using 15 years of excellent safety data. Contraception 2015;92:179-81. Copyright (c) 2018 Massachusetts Medical Society. 